\title{
Mothers' Social Communicative Adjustments to Young Children With Mild Developmental Delays
}

\author{
Michael J. Guralnick, Brian Neville, Mary A. Hammond, and Robert T. Connor \\ Center on Human Development and Disability, University of Washington
}

\begin{abstract}
The social communication and compliance patterns of 63 mothers interacting with their young children who had mild developmental delays in social play and instructional tasks were examined in a longitudinal study. Results were consistent with the hypothesis that mothers appropriately adjust their social communications in accordance with children's developmental characteristics and task demands. The extent of scaffolding specificity that mothers used in the instructional task also indicated a high level of sensitivity to children's developmental characteristics. Analyses conducted over a 2-year period revealed that adjustments were commensurate with children's emerging social communication abilities, suggesting that mothers of children with developmental delays continue to display social communication patterns that are supportive of their child's development.
\end{abstract}

The everyday interactions occurring between parents and children require adjustments in many aspects of parental social communications in accordance with their child's unique characteristics and interaction patterns. When appropriate adjustments do occur, parent-child relationships are not only more enjoyable, creating a flowing and balanced discourse between parents and child, but contain considerable developmental value as well (e.g., Bornstein \& Tamis-Lemonda, 1989; Landry, Smith, Swank, \& Miller-Loncar, 2000; Teti \& Candelaria, 2002; Tomasello \& Farrar, 1986; Vygotsky, 1978). Whether parental goals in these exchanges are primarily social or instructional at the moment, developmentally supportive social communications include maintaining high levels of responsiveness in various contexts, exerting control when needed, structuring the environment to highlight important features related to the goal as necessary, and providing timely and relevant information both spontaneously and in response to children's requests (Bradley, 2002; Bradley \& Corwyn, 2004; Guralnick, 2006). To achieve these needed adjustments, parents must be sensitive both to their child's global developmental char- acteristics, such as cognitive and language levels, as well as to their child's use of specific forms of social communications or overall level of communication activity occurring during the interaction. Of importance, young children with even mild developmental (cognitive) delays pose an especially difficult challenge for parents to make proper adjustments in various social contexts. This is due to many factors, including low levels of children's expressiveness, infrequent social initiations, and reduced levels of responsiveness (Spiker, Boyce, \& Boyce, 2002).

Early concerns regarding the ability of parents to make appropriate adjustments to young children with delays have been replaced by a more positive perspective (for reviews see Marfo, 1990; McCollum \& Hemmeter, 1997; and Hodapp, 1995). Specifically, although parents of children with delays are often found to be more directive in comparison to appropriately matched groups, they also display comparatively high levels of responsiveness (including complying with children's influence attempts), manage to maintain low levels of restricting or preventing children's behavior, and demonstrate an ability to facilitate their 
child's social and play interactions by providing information, feedback, and environmental support in a useful and timely manner (Cielinski, Vaughn, Seifer, \& Contreras, 1995; Crawley \& Spiker, 1983; Landry, Garner, Pirie, \& Swank, 1994; Landry, Miller-Loncar, \& Swank, 1998; Roach, Barratt, Miller, \& Leavitt, 1998; Tannock, 1988). Of note, upon closer analysis even the directives that parents use often took a form that provides child choice (suggestions) rather than commands (imperatives) to perform a specific behavior (e.g., Landry et al., 1998). Moreover, variations in the forms of directives employed by parents of children with delays appear to be sensitive to task demands (Hecht, Levine, \& Mastergeorge, 1993; Landry et al., 1994). Furthermore, and of considerable importance, within-group comparisons suggest that these parental social communication adjustments are linked both to children's global characteristics, particularly cognitive and language levels, and to children's level of social communication activity occurring in the interactive context. For the most part, parents' use of directives is greater for less competent and less communicatively interactive children (Crawley \& Spiker, 1993; Landry et al., 1994; Marfo, 1992).

Taken together, parents of young children with developmental delays appear to be intent on maintaining productive interactions with their children and meeting task demands, adjusting their social communications accordingly (see Bell, 1968). A form of social scaffolding is apparent as parents seek to provide the necessary structure even in unstructured, more socially oriented situations. When engaged in structured tasks, such as creating a product, instructional support or scaffolding is more apparent, as parents become more specific and directive to facilitate their child's success in the task (Landry et al., 1998). Accordingly, despite evidence suggesting that a small subset of parents may exhibit an inappropriate or intrusive style or maintain primarily a performance-oriented focus when interacting with their children (Cielinski et al., 1995; Mahoney, Fors, \& Wood, 1990), an overall positive interpretation of parental social communication adjustments to children with developmental delays appears warranted.

Nevertheless, the extant literature has many limitations, calling into question the generality of conclusions about parental adjustments to children with developmental delays. One concern is that children have been studied primarily during the early childhood period, frequently as infants and toddlers, with the vast majority of those young children diagnosed with Down syndrome. As children with Down syndrome exhibit etiologic-specific behaviors that are certain to influence parental adjustments (Guralnick, 2002; Hodapp, 2004; Spiker \& Hopmann, 1997), it is unclear whether findings to date extend to the larger population of children with developmental delays. Of greater concern, however, is the general absence of studies of parental adjustments beyond the early childhood period for children with developmental delays. Because expected developmental trajectories for children with delays beyond the early childhood period include increases in children's social communication abilities (Abbeduto \& Hesketh, 1997), this circumstance may well pose an additional challenge for parents to adjust their social communications in accordance with their child's emerging skills and abilities. Even some parents of typically developing children during early childhood may not use directives appropriately as their children's development advances (Landry, Smith, Swank, \& Miller-Loncar, 2000). Instructional tasks, in particular, require ongoing maternal adjustments, and differences in maternal directives, questions, and various aspects of support are evident even when comparing 6- and 8year-old typically developing children (Rogoff, Ellis, \& Gardner, 1984). Although cross-sectional studies can be of value, questions regarding maternal adjustments as a consequence of children's changing patterns of social communication are best addressed in longitudinal investigations. However, only one longitudinal study addressing this issue been carried out with children who have delays and that study involved a very small number of infants with Down syndrome (Maurer \& Sherrod, 1987).

Accordingly, to test the hypothesis regarding the generality of the appropriateness of parental adjustments, in this study we first examined the social communication adjustments of mothers of a heterogeneous group of preschool- and kindergarten-age children with mild developmental delays and then re-examined those adjustments 2 years later. Videotaped records of mothers and children participating in both free-play and teaching tasks were fully transcribed, and detailed measures of their social communications were obtained from these transcriptions. Of special interest to us were possible maternal adjustments not only to children's global characteristics, such as 
cognitive and language levels, but to the social communication levels of their child as well. By first controlling for global child characteristics, including cognitive and language levels as well as behavior problems, we obtained information with respect to how sensitive mothers were to their child as an interactive partner. Our longitudinal design also permitted assessments of stability and change of social communications for both mothers and children.

More specifically, to better understand the nature of maternal adjustments and to obtain as comprehensive a picture as possible, we examined and defined various directive forms of social communication as suggestions, imperatives, mitigated imperatives, and restrictions to alter a companion's behavior. Other major social communication categories analyzed consisted of the use of requests (to seek information) and statements (to provide information). Each of these major categories also contained subcategories to further characterize mother-child social communications. By utilizing both free-play and teaching tasks, we could also evaluate maternal adjustments to the demand characteristics of the two tasks. We took this a step further by assessing mothers' scaffolding behavior during the teaching task. Following the approach of Pratt, Kerig, Cowan, and Cowan (1988), we identified levels of specificity of instruction and correlated both with children's success in the teaching task and with children's characteristics. Finally, to assess maternal responsivity, we evaluated mothers' compliance to children's influence attempts (i.e., their use of requests and directives, particularly whether compliance varied with children's characteristics). This latter measure provided another useful index of maternal sensitivity, because maternal compliance represents both a willingness to respond and an understanding of a child's intent.

In summary, in this study we have provided a comprehensive assessment of the generality of social communication adjustments of mothers of children with mild developmental delays. Although the longitudinal nature of the design permits an examination of maternal adjustments to children's developing skills and abilities, it does not allow definitive statements to be made regarding the developmental effects of any adjustments observed. However, the nature of those adjustments evaluated at both time points, their correspondence to children's global characteristics and to children's specific social communication pat- terns, measures of mothers' responsiveness and sensitivity to their children, as well as maternal adjustments to task demands, provide important information as to whether observed adjustments are consistent with conditions likely to foster the development of children with mild developmental delays.

\section{Method}

\section{Participants}

Young children with mild developmental delays were recruited through contact with local school districts in a large metropolitan community. Participating school districts distributed announcements describing an opportunity to participate in a larger research project intended to promote children's peer relationships. Information was sent to all parents whose children had an Individualized Education Program (IEP) and who attended an inclusive (mainstreamed) preschool or kindergarten. Parents who were interested in participating contacted project staff directly, who then initiated a screening and identification process. To be included in this sample a child had to meet the following criteria: (a) be between 48 and 78 months of age, (b) have a current IEP, (c) be experiencing difficulties in peer-related social competence as expressed by parent concerns in a structured phone interview, (d) have a primary female caregiver (minimum of a 6-month relationship because mothers were our primary informants and participants), and (e) obtain a Full Scale IQ (FSIQ) score between 50 and 80 on the Wechsler Preschool and Primary Scale of Intelligence-Revised-WPPSI-R (Wechsler, 1989).

A number of exclusionary criteria also were established. Based on the Child Behavior Checklist-CBCL (Achenbach, 1991) completed by the mother (or other female caregiver) for each child (see below), children who scored in the clinical range were excluded from the study (a T score above 70 was established for children with developmental delays). A phone screening interview for mothers eliminated 6 children described as exhibiting major behavior problems. Two children were excluded because they obtained a $\mathrm{T}$ score of 70 or above on the CBCL. Similarly, exclusion occurred if mothers scored at or above the 95th percentile on the Parent domain of the Parenting Stress Index (Abidin, 1995). Three participants were excluded based on this criterion. These exclusionary criteria were established to minimize 
any disruptions to the portion of the larger project devoted to promoting children's peer relationships. Finally, children were excluded if English was not their primary language or if they had significant sensory or motor problems. No children were excluded on this basis.

Seventy-three children and families meeting our criteria were successfully recruited to participate; 63 completed the study over the 2-year period. Comparisons at Time 1 between children completing the study and those who did not were

Table 1. Child and Family Characteristics

\begin{tabular}{|c|c|c|c|c|}
\hline \multirow{2}{*}{$\begin{array}{l}\text { Child and family } \\
\text { characteristic }\end{array}$} & \multicolumn{2}{|c|}{ Time 1} & \multicolumn{2}{|c|}{ Time 2} \\
\hline & Mean/\% & $S D$ & Mean/\% & $\% S D$ \\
\hline \multicolumn{5}{|l|}{ Child demographic } \\
\hline Age (months) & 63.52 & 7.65 & 83.75 & 7.54 \\
\hline $\begin{array}{l}\text { Gender } \\
\text { (\% male) }\end{array}$ & 71.4 & & & \\
\hline $\begin{array}{l}\text { Ethnicity } \\
\qquad \text { (\% Caucasian) }\end{array}$ & 73.0 & & & \\
\hline \multicolumn{5}{|l|}{ Child characteristic } \\
\hline $\begin{array}{l}\text { WPPSI-R } \\
\quad \text { Full Scale IQ }\end{array}$ & 66.43 & 9.43 & 69.56 & 13.33 \\
\hline $\begin{array}{l}\text { Adaptive } \\
\text { Behavior }\end{array}$ & & & & \\
\hline Scales ${ }^{\mathrm{b}}$ & 69.46 & 8.63 & 74.89 & 11.29 \\
\hline TACL-R & & & & \\
\hline Total Scalec & 68.38 & 15.73 & 66.59 & 21.10 \\
\hline EOWPVT-Rd & 77.87 & 12.73 & 85.08 & 17.82 \\
\hline $\begin{array}{l}\text { CBCL Total } \\
\text { Behavior }\end{array}$ & & & & \\
\hline Problems ${ }^{\mathrm{e}}$ & 58.21 & 6.61 & 55.56 & 8.64 \\
\hline Family demographic & & & & \\
\hline $\begin{array}{l}\text { Family social } \\
\text { status }^{f}\end{array}$ & 51.46 & 13.01 & & \\
\hline $\begin{array}{l}\text { Mother's age } \\
\text { (years) }\end{array}$ & 37.06 & 5.05 & & \\
\hline $\begin{array}{l}\text { Marital status } \\
\quad \text { (\% partnered })\end{array}$ & 92.10 & & & \\
\hline
\end{tabular}

Note. $N=63$.

aWechsler Preschool and Primary Scale of Intelligence-Revised and Wechsler Intelligence Scale for Children-Third Edition. bVineland Adaptive Behavior Scales, total standard score. 'Test for Auditory Comprehension of Language-Revised, total score. ${ }^{\mathrm{d} E x p r e s s i v e ~ O n e ~ W o r d ~ P i c t u r e ~}$ Vocabulary Test-Revised, standard score. ${ }^{e}$ Child Behavior Checklist, T scores. ${ }^{\mathrm{f}}$ Hollingshead Four-Factor Index of Social Status. carried out on all child and family measures (see below) in Table 1. No significant differences were obtained for either continuous ( $t$ tests) or dichotomous (chi-square) measures (see Table 1). Diagnostic information provided by parents at the end of the study indicated that most children received only categorical diagnoses (e.g., static encephalopathy, developmental delay) or no diagnosis whatsoever, with meaningful etiologic diagnoses infrequently reported (see Guralnick, Connor, Neville, \& Hammond, 2006).

\section{Child and Family Characteristic Measures}

Children were evaluated by psychologists who had extensive prior experience working with young children who had developmental delays. The following child measures were administered: (a) WPPSI-R was used to obtain FSIQ scores. Older children were assessed with the Wechsler Intelligence Scale for Children-Third Edition-WISCIII (Wechsler, 1991). The standard battery of tests (5 verbal and 5 performance) was administered; (b) the Vineland Adaptive Behavior Scales (Sparrow, Balla, \& Cicchetti, 1984) was administered to mothers: standard scores were obtained for four domains, but only the total score was used in this analysis; (c) the Test for Auditory Comprehension of Language-Revised-TACL-R (Carrow-Woolfolk, 1985): although the TACL-R yields four standardized scores, only the total score was used in this analysis; (d) The Expressive One Word Picture Vocabulary Test-Revised-EOWPVT-R (Gardner, 1990): the obtained raw score was converted to a standard score that was used for analysis; and (e) CBCL: mothers rated the frequency of different behavior problems from a 118 -item questionnaire using a 3-point scale, and only the total score was used for analysis.

Standard demographic information about the family was also obtained (marital status, number of children, ethnicity, educational and occupational status, and income) via self-reports from mothers. The Hollingshead Four Factor Index of Social Status (Hollingshead, 1975) was used to calculate a measure of family social status (range $=$ 8 to 66$)$.

\section{Experimental Design and Procedure}

Following recruitment procedures outlined above, families whose children met all inclusionary criteria received a packet of materials in the mail containing the various scales and question- 
naires. Mothers were then scheduled to bring their child to the laboratory for interviews and for mother-child observation sessions. This procedure was repeated approximately 2 years later. $\mathrm{Ob}$ servations took place on 2 consecutive days, with one free-play (20 min each) and one teaching task (15 min each) session scheduled each day.

\section{Laboratory Observations of Mother-Child Interactions}

The focal child and mother were brought to the parent-child laboratory for mother-child free play task and teaching task observations. This laboratory contained three main experimental suites for video taping and behavioral testing. For the free-play task, the playroom in the laboratory was minimally furnished but contained a variety of toys, including those that could be used for pretend play (Sesame Street play set, stuffed animals, cars, dolls), and construction (blocks) as well as board games, coloring books, and puzzles. After entering the laboratory suite, the mother was informed that:

Now we'd like to watch — [your child] playing with you. Play however you would like for the next 20 mins. Feel free to use any of these toys, or if there are things you like to play that do not include these toys, you can do that as well. Just try to play as you normally would. I'll be back in 20 mins with another activity for you.

After a break, the mother and child were asked to build with Tinkertoys in the teaching task. The goal was to present the child with a challenge for which he or she would need help so that the mother's ability to organize and instruct could be observed. Tinkertoy building was selected for this observation because the task can vary from quite complex to quite simple, depending on the abilities of the child and the level of support provided by the mother. Constructed models and picture models were presented; the child's task was to build one just like it. The Tinkertoys and the first model were placed on the floor and the child was told:

Now I would like you to play with some Tinkertoys. First let's dump them on the floor. [The model is presented] This is a model of what I'd like you to make with them. I'd like you to make another one that looks just like this one.

The mother was then given the following instructions: "Your job is to provide whatever help — [your child] needs to be able to build it. When - [your child] finishes with this one, I'll bring in another one.” At Time 1, children were presented first with a constructed model with a simple design (such as a swing set), which they used to build their own construction. Once this was completed, a second, more complicated constructed model was presented. If the child completed both of these in less than $15 \mathrm{~min}$, the paper instructions from the Tinkertoy set were provided, and the child was asked to select a model and build it. The same procedure occurred at Time 2, except that the dyad was asked to make a duplicate of the model presented on the paper instruction rather than the constructed model. Two views of the paper model were shown; one in which the pieces were separated and one that was completely connected. All children, regardless of their abilities, needed assistance with the task.

\section{Mother-Child Interaction Coding Schemes}

Social communication and compliance measures. Social communication and compliance patterns for both mothers and children were coded for each of the two free-play task and teaching-task sessions. Before coding could be carried out, all sessions were transcribed verbatim from the videotaped observations. Turns were first identified, with each turn consisting of utterances produced in sequence by one participant, which continued until the participant signaled that a response was expected or was interrupted by the other participant (see Garvey, 1986; Sacks, Schegloff, \& Jefferson, 1978). If the participant paused as if expecting a response (for $5 \mathrm{~s}$ ) and the other participant made no verbal or nonverbal response, the next participant's utterance was considered the beginning of a new turn. "No response" was recorded for the intervening participant turn. Both verbal and nonverbal social communications were transcribed. A nonverbal utterance was defined as a distinct communicative act that may be an initiation of an activity (e.g., handing an object to the other participant) or a response to a request or directive (e.g., responding nonverbally to a question by pointing or head nod). The absence of a response to a request or directive (see below) was coded as a separate turn. Therefore, the coding scheme was based on a series of alternating turns between mother and child. Rules regarding the use of vocalizations, gestures, and other forms of communication (e.g., turn boundaries defined by the 5-s pause) were provided to transcribers.

Following the general system outlined by Black and Logan (1995), we then coded each utterance (verbal and nonverbal) in each turn in 
terms of its social communicative function as either a statement (conveying information about facts), request (posing a question), or directive (seeking to obtain a behavioral response). Turns were typically brief, but as many as nine social communications could be coded in any turn. These categories were mutually exclusive and exhaustive. Detailed definitions, along with the subcategories that were coded for each of the main social communication categories, are as follows:

1. Statements: Conveying information about facts, activities, feelings, or interest. No direct obligation is placed on the other person to respond.

Explanation: description or narration of the ongoing play activity. Includes facts and other information about objects or events. Can occur in response to a previous turn or as a spontaneous statement. Example: "It's a Sesame Street toy."

Back-channel feedback: communicative signals that provide supportive feedback or simply indicate that one is listening. Example: "uh-huh," "hmm," or a head nod.

Positive emotion: describes personal emotion or emotional expression that is positive (e.g., happiness, excitement) or makes positive evaluations referenced outside the current freeplay task or teaching-task situation. Example: "I like doing this."

Negative emotion: describes personal emotion or emotional expression that is negative (e.g., anger, sadness). Includes negative evaluations referenced outside the current free-play task or teaching task. Example: "I'm angry."

Positive feedback: a statement indicating that the other person's actions or statements are correct. Example: "Yes, that's the way to do it."

Corrective feedback: a statement indicating that the other person's actions or statements are incorrect. Example: "No, that doesn't go there."

Praise: an individual makes a positive evaluation of the qualities, skills, abilities, or behavior of the other person in the setting. Example: "You're good at this."

Criticism: an individual makes a negative evaluation of the qualities, skills, abilities, or behavior of the other person in the setting. Example: "I don't like it when you scream."

2. Requests: Posing a question to another person, thereby placing an obligation to respond. The intent is to obtain a statement from the other person.

Request explanation: soliciting statements of explanation (see above) from the other person. Included are requests for descriptions of an ongoing activity, an explanation about how to do something in the free-play or teaching activity, information about what the other is doing, or clarification of a previous utterance. Example: "What is this?"

Request feedback: soliciting feedback about the quality of one's performance from the other person. Example: "Is this right?"

Request emotion: soliciting a statement of feelings from the other person. Example: "Are you angry?"

Request personal evaluation: soliciting a statement of personal evaluation (praise or criticism) from the other person. Example: "Am I good at this?"
3. Directives: Seeking to obtain a behavioral response from the other person. An obligation to respond with action is placed on the other person.

Suggestion: proposing a specific activity or offering an object to another person intended to produce a behavioral response but done in a manner that allows the person a choice regarding participation. Example: "You could put the block here."

Imperative: directing another person to perform some action with no power to decline implied by the utterance. Example "Pick up the blue one."

Mitigated imperative: mitigating an imperative by use of "please" or "okay?" or similar forms presented at the beginning or end of the utterance. Example: "Please pick up the blue one."

Restriction: demanding that the other person stop an activity. Example: "Don't do that."

In addition to the three major social communication categories and their subcategories, the effectiveness of each influence attempt (i.e., request or directive) was determined. One of the following four compliance categories was coded for each request or directive issued by either participant: (a) Comply: fully complies with request or directive, correctness of the answer (to a request), or success of a response (to a directive) was not considered but must be relevant; (b) Deferral: the other person responds by deferring compliance to a later time, by making it contingent on the performance of some other action or by defining a time within the session when a decision will occur: relevant questions about a request or directive are also coded as a deferral; (c) Ignore: neither consent nor refusal is evident, with the person not responding or acknowledging the request or directive; and (d) Refuse: person makes a statement or physical action that is in opposition to the request or directive. A no opportunity to comply category was also available in the event that there was insufficient time to comply (e.g., person issuing a directive carries out the action themselves almost immediately).

Scaffolding measures. A second coding scheme was applied to the teaching task to examine the degree of structured support or scaffolding that mothers provided for their children. The coding system was based on that developed by Wood and Middleton (1975) and modified by Pratt et al. (1988).

A scaffolding turn was defined as an effort by the mother to provide direction to her child in connection with a specific activity or goal related to the teaching task. The mother's focus was on achieving some action on the part of her child. Each scaffolding turn was then coded into one of 
six levels varying in terms of the degree of support provided, following a scheme similar to that of Pratt et al. (1988):

Level 1. General Verbal Start: mother prompts child to begin or reorient to task ("Let's try to do this").

Level 2. Hint: some information is provided (indirect) but no identification of materials needed or placement of materials ("Look at which way it is").

Level 3. Descriptive Instruction: provides information about general type of materials needed ("Can you find a green one now?") or general area where materials need to be placed ("Put that on"-but not specify where).

Level 4. Identify specific material: direction about a specific next piece is provided ("You need that one over there").

Level 5. Identifies specific placement of specific material: instructs child (verbally or by pointing) to connect a specific piece to a specific place in the construction ("Put the green one here").

Level 6. Demonstrate: mother shows how pieces fit and then directs the child to complete the action in the same way ("See how you do it?"). Turns in which no maternal scaffolding occurred in the teaching task were also identified.

For each identified scaffolding turn, the child's success in completing the response represented by the scaffolding direction also was coded. To be coded as successful, responses were required to match the specificity of the scaffolding support provided by the mother and must have been completed before the mother provided the next scaffold. Finally, for all nonscaffolding turns, we coded whether the child was on task (i.e., actively engaged in the building task). This on-task measure provided information about the child's ability to continue to successfully work toward completing the task in the absence of maternal scaffolding. A detailed coding manual for the scaffolding and related child measures can be obtained from the first author.

\section{Reliability}

Reliability was first calculated for transcription of mother-child interactions. Two transcribers independently prepared transcripts for $20 \%$ of the free-play task and teaching-task sessions. Interrater reliability in terms of percentage agreement was calculated for words, punctuation, and turn boundaries. Agreement was high in all instances: $87 \%$ for words (range $=77 \%$ to $95 \%$ ); $86 \%$ for punctuation (range $=80 \%$ to $96 \%$ ); and $84 \%$ for turns (range $=72 \%$ to $95 \%$ ).

For the social communication and compliance codes, coders unaware of the study hypotheses were initially trained using pre-coded reliability tapes. Pilot tapes were then coded until coders achieved Cohen's kappa of .70 or greater with an experienced coder. Training averaged approximately 2 months and was carried out separately for the social communication and compliance codes. Interrater reliability was then obtained for $20 \%$ of the free-play task and teaching task sessions. Cohen's kappa was computed between the head coder and each of the other coders for the social communication codes for the full matrix (including subcategories) and separately for the compliance categories based on a series of 15-min segments. For the free-play task, coders obtained a mean kappa of .76 for social communication and .66 for compliance. For the teaching task, coders obtained a mean kappa of .74 for social communication and .66 for compliance. Intraclass correlation coefficients were also calculated for the three main social communication and compliance codes to be used in the analysis (see Mitchell, 1979). Correlations were uniformly high, ranging from .72 to $.99(M=.95)$.

For the scaffolding measures, coders were trained on pre-coded reliability tapes. Reliability was obtained for turns without scaffolding, maternal scaffolding level, child success, and child on-task. Prior to coding, coders met the minimum reliability criterion based on all mother and child measures, overall kappa $=.76$. A kappa of .79 was obtained for $30 \%$ of the sessions based on all measures. Intraclass correlations were then calculated separately for each measure used in the scaffolding analysis: no scaffolding (.93), scaffolding level (.96), child success (.91), and child on-task (.93).

\section{Results}

As indicated earlier, approximately half the children in this sample participated in an intervention to promote their peer-related social competence following Time 1 observations (Guralnick et al., 2006). The primary focus of the current study, however, was mother-child interactions evaluated at two time periods. Consequently, all analyses reported here were first carried out controlling for condition (intervention vs. control), which produced negligible effects.

Descriptive data for the main social communication measures for the free-play and teaching tasks for mothers and children at each time point summed over the two sessions are presented in Tables 2 and 3. No subcategories are included for either statements or requests because each was dominated by one social communication form for both members of the dyad across tasks and time. 
Table 2. Social Communication Measures at Both Time Points for the Free-Play Task

\begin{tabular}{|c|c|c|c|c|c|}
\hline \multirow{2}{*}{$\begin{array}{l}\text { Social communication } \\
\text { measure }\end{array}$} & \multicolumn{2}{|c|}{ Time 1} & \multicolumn{2}{|c|}{ Time 2} & \multirow{2}{*}{$\begin{array}{l}\text { Stability } \\
\text { correlations }\end{array}$} \\
\hline & Mean & $S D$ & Mean & $S D$ & \\
\hline \multicolumn{6}{|l|}{ Mother } \\
\hline No. of turns & 255.29 & 48.20 & 247.37 & 49.95 & $.52 * * *$ \\
\hline Total communications & 458.11 & 121.68 & 444.62 & 105.11 & $.67 * * *$ \\
\hline Communications per turn & 1.81 & .40 & 1.81 & .34 & $.70 * * *$ \\
\hline Total statements & .50 & .09 & .59 & .09 & $.64 * * *$ \\
\hline Total requests ${ }^{\mathrm{a}}$ & .29 & .08 & .24 & .08 & $.61 * * *$ \\
\hline Total directives ${ }^{a}$ & .20 & .08 & .18 & .08 & $.47 * * *$ \\
\hline Imperatives ${ }^{\mathrm{b}}$ & .53 & .13 & .60 & .13 & $.27 *$ \\
\hline Suggestions ${ }^{b}$ & .42 & .13 & .35 & .13 & $.30 *$ \\
\hline \multicolumn{6}{|l|}{ Child } \\
\hline No. of turns & 255.22 & 48.06 & 247.08 & 50.05 & $.52 * * *$ \\
\hline Total communications & 307.68 & 82.68 & 313.17 & 79.49 & $.39 * *$ \\
\hline Communications per turn & 1.21 & .28 & 1.27 & .24 & $.54 * * *$ \\
\hline Total statements & .75 & .09 & .74 & .09 & .23 \\
\hline Total requests ${ }^{a}$ & .11 & .06 & .13 & .07 & $.49 * * *$ \\
\hline Total directives $^{a}$ & .14 & .08 & .14 & .07 & .10 \\
\hline Imperatives ${ }^{\mathrm{b}}$ & .61 & .17 & .67 & .14 & .15 \\
\hline Suggestions ${ }^{\mathrm{b}}$ & .27 & .17 & .24 & .15 & .24 \\
\hline
\end{tabular}

Note. $N=63$.

aProportion. Proportion of directives.

${ }^{*} p<.05 .{ }^{* * p}<.01 .{ }^{* * *} p<.001$.

Statements were primarily in the form of explanations $(M=.74)$, whereas the preponderance of requests were seeking explanations $(M=.82)$. For directives, however, both suggestions and imperatives occurred frequently and were included in the tables. The use of mitigated imperatives and restrictions was extremely low (approximately $5 \%$ ). Based on these and related data, we first conducted analyses to examine change and stability of these measures over time. This was followed by analyses of mothers' compliance to children's requests and directives and mothers' adjustments across tasks, as well as correlational analyses of mothers' adjustments to their child's global characteristics and level of communication activity. Finally, analyses of maternal scaffolding during the teaching task were carried out.

\section{Change and Stability of Social \\ Communication Measures Over Time}

To examine changes over time for the freeplay task, we first conducted MANOVAs separately for mothers and children for the following main measures: total communications; commu- nications per turn; and the proportion of statements, requests, and directives. Significant effects for time were obtained for both the mother, $F(5,58)=17.06, p<.001$, and child, $F(5,58)=$ 3.06, $p<.05$. Follow-up $t$ tests revealed that mothers' overall social communications to their child, as indexed by the number of turns, total communications, and communications per turn measures, did not change over the 2-year period. However, the distribution of social communications for each of the three main categories (proportion measures) did change over time. Specifically, mothers used a higher proportion of statements in Time 2 than in Time $1, t(62)=8.31, p$ $<.001, d=1.48$, but decreased their proportional use of directives, $t(62)=2.67, p<.05, d=.48$, and requests, $t(62)=6.07, p<.001, d=1.08$. However, the proportion of directives that were imperatives increased over time, $t(62)=3.58, p$ $<.01, d=.64$, whereas the proportion of suggestions that were directives decreased, $t(62)=$ $4.11, p<.01, d=.73$. For children, overall social communications increased significantly over time but only for the communications per turn mea- 
sure, $t(62)=2.24, p<.05, d=.40$. Change over time also occurred for the main social communication categories. Specifically, the proportion of children's requests increased over time, $t(62)=$ $2.40, p<.05, d=.43$, as did the proportion of directives that were imperatives, $t(62)=2.04, p<$ $.05, d=.37$. None of the other social communication category measures in Table 2 were statistically significant.

Accordingly, over time, mothers reduced their control during social exchanges in the free-play task, directing and requesting their children less often despite an increase in the proportion of directives that were imperatives. Mothers also increased their proportional use of statements, perhaps in response to the increase in their child's requests over the 2-year period. Children communicated more extensively with their mothers over time as reflected in the communications per turn measure. They also used a higher proportion of directives that were imperatives and had a higher proportion of requests.

For the teaching task (see Table 3), we conducted MANOVAs for the time variable separate- ly for mothers and children for the six main dependent measures. This produced a significant time effect for both mothers, $F(5,57)=11.27$, $p$ $<.001$, and children, $F(5,57)=3.78, p<.01$. Follow-up analyses indicated that all three overall social communication measures decreased for mothers over time (number of turns, $t[61]=3.03$, $p<.01, d=.58$; total communications, $t[61]=$ 5.53, $p<.001, d=.46$; and communications per turn, $t[1]=2.48, p<.05, d=.45)$. As in the free-play task, the proportion of mothers' statements increased significantly over time, $t(61)=$ $4.95, p<.001, d=.89$, whereas the proportions of requests, $t(61)=2.00, p<.05, d=.36$, and directives, $t(61)=3.05, p<.001, d=.55$, decreased. No changes over time for the proportion of imperatives or suggestions that were directives were detected. For children, a decrease in overall communications was found only for the number of turns, $t(61)=3.03, p<.01, d=.54$, but, similar to the free-play task, children increased the number of communications per turn over time, $t(61)=3.05, p<.01, d=.55$. However, the proportions for the three main social communication

Table 3. Social Communication Measures at Both Time Points for the Teaching Task

\begin{tabular}{|c|c|c|c|c|c|}
\hline \multirow{2}{*}{$\begin{array}{l}\text { Social communication } \\
\text { measure }\end{array}$} & \multicolumn{2}{|c|}{ Time 1} & \multicolumn{2}{|c|}{ Time 2} & \multirow{2}{*}{$\begin{array}{c}\text { Stability } \\
\text { correlations }\end{array}$} \\
\hline & Mean & $S D$ & Mean & $S D$ & \\
\hline \multicolumn{6}{|l|}{ Mother } \\
\hline No. of turns & 263.44 & 52.94 & 240.81 & 60.54 & $.53 * * *$ \\
\hline Total communications & 553.76 & 137.07 & 475.74 & 133.78 & $.64 * * *$ \\
\hline Communications per turn & 2.14 & .53 & 2.01 & .47 & $.66 * * *$ \\
\hline Total statementsa & .39 & .08 & .43 & .09 & $.58^{* * *}$ \\
\hline Total requestsa & .14 & .07 & .12 & .05 & $.49 * * *$ \\
\hline Total directives ${ }^{a}$ & .48 & .09 & .44 & .09 & $.49 * * *$ \\
\hline Imperatives ${ }^{\mathrm{b}}$ & .53 & .14 & .52 & .13 & .39 \\
\hline Suggestions ${ }^{b}$ & .42 & .14 & .45 & .14 & $.44 * * *$ \\
\hline \multicolumn{6}{|l|}{ Child } \\
\hline No. of turns & 261.48 & 53.43 & 240.06 & 60.73 & $.53 * * *$ \\
\hline Total communications & 246.61 & 86.68 & 249.92 & 95.74 & $.56 * * *$ \\
\hline Communications per turn & .93 & .23 & 1.03 & .27 & $.52 * * *$ \\
\hline Total statementsa & .78 & .09 & .78 & .09 & $.51 * * *$ \\
\hline Total requests ${ }^{\mathrm{a}}$ & .14 & .09 & .15 & .08 & $.54 * * *$ \\
\hline Total directives ${ }^{\mathrm{a}}$ & .08 & .05 & .07 & .05 & $.31 *$ \\
\hline Imperative ${ }^{\mathrm{b}}$ & .67 & .21 & .77 & .23 & .09 \\
\hline Suggestions ${ }^{b}$ & .24 & .21 & .14 & .16 & .02 \\
\hline
\end{tabular}

Note. $N=62$.

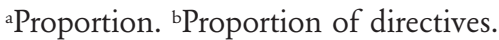

$* p<.05 . * * p<.001$. 
categories did not change for this task. Analyses of the directive subcategories did indicate that the proportion of directives that were imperatives increased over time, $t(61), 3.23, p<.01, d=.58$, and the proportion of suggestions that were directives decreased, $t(61)=3.29, p<.01, d=.66$.

Once again, the pattern for the teaching task indicated that mothers reduced their control over the 2-year period. They also communicated less in general over time, perhaps in response to children's increased levels of communication, but increased their proportional use of statements. Children also used a higher proportion of imperatives that were directives over time.

Both the extent of social communications and the proportional use of the social communication categories for both mothers and children were generally moderately or highly stable over time. Tables 2 and 3 present Pearson stability correlations. A particularly stable measure for both mothers and children was the number of communications per turn.

\section{Mother Compliance to Their Child's Requests and Directives}

We evaluated mothers' compliance to their child's requests and directives using proportion compliance measures that served as indices of responsiveness. For the free-play task, mother compliance was high for the full compliance measure at Times 1 and 2, .60 and .64, respectively. When the deferring compliance subcategory was included (the total referred to as positive compliance), the respective proportions for Times 1 and 2 were .77 and .77, respectively. Neither compliance measure changed over the 2-year period, and only the positive compliance measure was stable over time, $r=.29, p<.05$.

For the teaching task, mothers' compliance to their children's requests and directives was also high. Full compliance proportion for Times 1 and 2 was .60 and .71, respectively, whereas corresponding proportions for positive compliance proportion were .68 and .75 . For this task, both compliance proportion measures increased significantly over time: full compliance, $t(61)=4.21$, $p<.001, d=.76$; positive compliance, $t(61)=$ 3.43, $p<.01, d=.62$. Again, only the positive compliance measure showed stability over time, $r$ $=.29, p<.05$.

\section{Mothers'Adjustments Across Tasks}

To evaluate the effect of task for mothers' adjustments, we carried out separate MANOVAs for each time period. The total communication measure was not included in the analyses because it varied with the number of turns that differed between the tasks. Significant task effects were obtained for both Time $1, F(4,58)=118.89, p<$ .001 , and Time $2, F(4,58)=128.94, p<.001$.

Follow-up analyses revealed that mothers employed more communications per turn in the teaching task than free play at Time $1, t(61)=$ 8.49, $p<.001, d=1.53$, and Time $2, t(61)=$ 4.32, $p<.001, d=.78$. Similarly, mothers employed a substantially higher proportion of directives in the teaching task than the free-play task at both Time $1, t(61)=22.10, p<.001, d=$ 3.97, and Time 2, $t(61)=22.5, p<.001, d=$ 4.04 (see Tables 2 and 3). In fact, nearly half of mothers' social communications were directives in the teaching task. At Time 2, the proportion of directives that were imperatives, however, were lower in the teaching task, $t(61)=3.86, p<.001$, $d=.69$, whereas the proportion of directives that were suggestions was higher, $t(61)=4.54, p<$ $.001, d=.82$. Consequently, although the proportion of directives was much higher in the teaching task than the free-play task, the form these directives took over time in the teaching task gave children options to respond more often. Correspondingly, the proportion of mothers' statements at both time points (Time 1: $t[61]=$ $11.89, p<.001, d=2.14$; Time $2: t[61]=13.17$, $p<.001, d=2.37$ ) and the proportion of requests at both time points (Time 1: $t[61]=16.52, p<$ $.001, d=2.97$; Time 2: $t[61]=13.70, p<.001$, $d=2.46)$ were higher during the free-play task than the teaching task.

Although adjusting to the task, mothers nevertheless displayed a consistent pattern of social communications directed to their child across tasks. Task stability correlations were significant for all main measures at Time 1 (communications per turn, $r=.80, p<.001$; proportion statements, $r=.61, p<.001 ;$ proportion requests, $r=.52$, $p<.001$; and proportion directives, $r=.28, p<$ .05 ) and at Time 2 (communications per turn, $r$ $=.63, p<.001 ;$ proportion statements, $r=.47$, $p<.001$; proportion requests, $r=.52, p<.001$; and proportion directives, $r=.39, p<.01$ ).

\section{Mothers' Adjustments to Global Child Characteristics}

To determine whether children's global characteristics and social communication levels were 
associated with mothers' social communications and their compliance to children's requests and directives (responsivity), a series of zero-order correlations was first computed. For both tasks and time points, the number of total communications; communications per turn, the proportions of mothers' requests, statements, and directives (and proportion of directives that were imperatives) and the proportion of their full and positive compliance were correlated with children's CA, cognitive level (FSIQ), general language level (TACL$\mathrm{R}$ total), expressive language level (EOWPVT-R), and behavior problems (CBCL total problems).

Our primary interest focused on the pattern and consistency of significant correlations. Given the large number of correlations conducted, little confidence should be given to any individual finding. As can be seen in Table 4, mothers' social communications were most frequently associated with their child's cognitive level. Most consistent was mothers' total communications, which occurred at a higher rate to children with lower FSIQ scores at both time points for the teaching task and at Time 2 for the free-play task. Proportionally more directives also were issued to children at lower cognitive levels at Time 1 but not at Time 2 for both tasks. Of note, the proportion of directives that were imperatives was not significantly correlated with any child measure.

For the language measures, the proportion of mothers' statements were positively correlated with the overall language measure (TACL-R) for the free-play task at Time 1 and at both time points for the teaching task (see Table 4). Proportion of statements was also positively correlated with children's expressive language at Time 2 for

Table 4. Correlations Between Mother Free-Play and Teaching Task Measures and Global Child Characteristics by Time

\begin{tabular}{|c|c|c|c|c|c|c|c|c|}
\hline \multirow{3}{*}{$\begin{array}{l}\text { Mother social } \\
\text { communication }\end{array}$} & \multicolumn{8}{|c|}{ Global child characteristic } \\
\hline & \multicolumn{2}{|c|}{ CA } & \multicolumn{2}{|c|}{ Full-Scale IQ } & \multicolumn{2}{|c|}{ TACL-R Total Scale } & \multicolumn{2}{|c|}{ EOWPVT-Rc } \\
\hline & Time 1 & Time 2 & Time 1 & Time 2 & Time 1 & Time 2 & Time 1 & Time 2 \\
\hline \multicolumn{9}{|l|}{ Free-play task } \\
\hline Total communications & .093 & .046 & -.218 & $-.259 *$ & -.013 & -.195 & -.053 & -.120 \\
\hline $\begin{array}{l}\text { Communications per } \\
\text { turn }\end{array}$ & .035 & .075 & -.078 & .046 & .045 & -.003 & -.012 & .053 \\
\hline Total statements ${ }^{a}$ & .024 & .002 & $.299 *$ & -.037 & $.335 * *$ & .114 & .238 & -.023 \\
\hline Total requests ${ }^{\mathrm{a}}$ & -.217 & -.024 & -.073 & -.120 & -.184 & -.121 & -.188 & -.077 \\
\hline Total directives $^{a}$ & .181 & -.012 & $-.295^{*}$ & .124 & -.204 & -.022 & -.085 & .081 \\
\hline Imperative $^{a}$ & .176 & .005 & -.117 & .215 & -.060 & .228 & .023 & .014 \\
\hline Full complya & .184 & -.038 & .085 & .012 & -.019 & .070 & .100 & .038 \\
\hline Positive complya & .160 & .061 & -.080 & -.044 & -.178 & .046 & -.079 & .009 \\
\hline \multicolumn{9}{|l|}{ Teaching task } \\
\hline Total communications & -.142 & -.213 & $-.371 * *$ & $-.492 * * *$ & -.176 & $-.347 * *$ & -.231 & $-.261 *$ \\
\hline $\begin{array}{l}\text { Communications per } \\
\text { turn }\end{array}$ & -.062 & -.033 & -.077 & -.055 & -.010 & -.093 & -.030 & -.058 \\
\hline Total statementsa & $.322 *$ & .204 & $.466 * * *$ & .215 & $.322 *$ & $.312 *$ & .230 & $.269 *$ \\
\hline Total requests ${ }^{\mathrm{a}}$ & -.115 & .034 & -.016 & -.017 & -.035 & -.146 & .052 & -.036 \\
\hline Total directives ${ }^{a}$ & -.185 & -.249 & $-.425 * *$ & -.233 & $-.299 *$ & -.235 & $-.258 *$ & $-.276^{*}$ \\
\hline Imperative & .013 & .105 & -.011 & .031 & -.108 & -.012 & -.178 & -.119 \\
\hline Full complya & .171 & .078 & $.257^{*}$ & .117 & -.022 & .145 & .077 & -.029 \\
\hline Positive complya & .123 & .089 & $.270 *$ & .105 & -.024 & .188 & .069 & -.013 \\
\hline
\end{tabular}

Note. Free play $n=63$, teaching task $n=62$.

aProportion. ${ }^{\mathrm{b}}$ Test for Auditory Comprehension of Language-Revised, total score. 'Expressive One Word Picture Vocabulary Test-Revised, standard score.

${ }^{*} p<.05 .{ }^{* * p}<.01 .{ }^{* * *} p<.001$.

(C) American Association on Intellectual and Developmental Disabilities 
the teaching task. Also for the teaching task, mothers' total communications were negatively correlated with both language measures at Time 2. The proportion of mothers' directives was also associated with both child language measures, but only for the teaching task. A higher proportion of mothers' directives was addressed to children with lower language levels. Child behavior problems were not correlated with any measure of mothers' social communications at Time 1 and inconsistently at Time 2 and are not included in the table. This is not an unexpected finding given that children with significant behavior problems were excluded from this sample.

Accordingly, mothers generally communicated more and were more directive when interacting with children at lower cognitive and language levels. Correlations were most consistent at Time 2 and in the teaching task. A higher proportion of statements was generally addressed to children at higher cognitive and language levels.

As noted earlier, the proportion of mothers' compliance to their child's requests or directives was high (overall $M=.74$ ). As indicated in Table 4, no significant correlations were found for either compliance measure (full or positive) with any of the global child characteristic measures for the free-play task. For the teaching task, mothers did comply proportionally more often (positive compliance only) to children at higher cognitive levels, but only at Time $1, r=.27, p<.05$. Consequently, despite wide variations in children's $\mathrm{CA}$, cognition, and language, mothers were able to maintain a high level of responsiveness to their child's requests and directives for both tasks and time periods.

\section{Mothers'Adjustments to Children's Overall Level of Communication}

In the next analysis, we determined whether the forms of mothers' social communication were also related to their child's overall level of communication activity after controlling for global child characteristics (CA, cognition, language lev$\mathrm{el}$, and behavior). As noted previously, the communications per turn measure was especially stable across time and appeared to represent the level of communication activity in a turn required by each participant to communicate their intent as clearly and effectively as possible. For example, high communication activity within a turn for mothers may have consisted of a statement of the task ahead to orient the child followed by one or more related directives.

As seen in Table 5, mothers did indeed make these more fine-tuned adjustments, altering their social communications to their child's communication activity level. Most notable was the finding that for both tasks and time periods, a strong inverse association was found between mothers' communications per turn and children's communications per turn. Even when controlling for global child characteristics, mothers were clearly adjusting their level of communication activity to that of their child, communicating more extensively to children who displayed lower levels of communication activity. Mothers also addressed a higher proportion of requests to children at higher levels of communication activity for both tasks, but only at Time 1, and issued proportionally more statements to those children at Time 2 in the free-play task. In contrast, mothers addressed a higher proportion of directives to children with lower communication activity only in the freeplay task but at both time points, whereas the proportion of directives that were imperatives were higher to children at lower levels of communica-

Table 5. Partial Correlations Between Mothers' Social Communication Measures and Children's Communications Per Turn (Communication Activity) for Both Tasks and Time Periods

\begin{tabular}{|c|c|c|}
\hline \multirow[b]{2}{*}{ Mother } & \multicolumn{2}{|c|}{$\begin{array}{c}\text { Child communications } \\
\text { per turn }\end{array}$} \\
\hline & Time 1 & Time 2 \\
\hline \multicolumn{3}{|l|}{ Free-play task } \\
\hline $\begin{array}{l}\text { Communications } \\
\text { per turn }\end{array}$ & $-.724 * * *$ & $-.652 * * *$ \\
\hline Total statements ${ }^{a}$ & -.015 & $.302 *$ \\
\hline Total requests ${ }^{\mathrm{a}}$ & $.332 *$ & .035 \\
\hline Total directives ${ }^{a}$ & $-.340 * *$ & $-.368 * *$ \\
\hline Imperative $^{a}$ & -.120 & -.052 \\
\hline \multicolumn{3}{|l|}{ Teaching task } \\
\hline $\begin{array}{l}\text { Communications } \\
\text { per turn }\end{array}$ & $-.760 * * *$ & $-.717 * * *$ \\
\hline Total statements & -.085 & .156 \\
\hline Total requests ${ }^{a}$ & $.318^{*}$ & -.031 \\
\hline Total directives ${ }^{a}$ & -.225 & -.142 \\
\hline Imperative $^{\mathrm{a}}$ & $-.315^{\star}$ & -.058 \\
\hline
\end{tabular}

aProportion.

${ }^{*} p<.05 . *{ }^{* *} p<.01 .{ }^{* * *} p<.001$. 
tion activity in the teaching task at Time 1 . Accordingly, the strongest and most consistent findings were that mothers had higher levels of communication activity and were more directive when children's levels of communication activity were lower, even after controlling for global child characteristics.

\section{Maternal Scaffolding}

Mothers attempted some form of scaffolding in the teaching task about half the turns in both time periods, and the number of turns in which there were no scaffolding attempts did not differ from Time 1 to Time 2 (see Table 6). The frequency distributions for the six levels of scaffolding specificity are also presented in Table 6 and indicate extensive use of mainly the first four levels. To examine changes over the 2-year period, we first conducted a MANOVA for the proportion measures for the levels of scaffolding specificity, which demonstrated a significant time effect, $F(6,56)=14.30, p<.001$. Follow-up $t$ tests revealed that mothers reduced their reliance on higher scaffolding levels over time (Level 4: $t(61)$ $=2.22, p<.05, d=.40$; Level 5: $t(61)=4.36$, $p<.001, d=.78$; but not Level 6). General verbal start (Level 1) was also relied on less frequently over time, $t(61)=2.90, p<.01, d=.52$, but the use of hints (Level 2) and specific verbal instruction (Level 3) increased over the 2-year period, $t(61)=5.68, p<.001, d=1.02 ; t(61)=3.05, p$ $<.05, d=.55$, respectively.

Children were on-task a substantial proportion of the turns at both Times 1 and $2(M \mathrm{~s}=$ .65 and .74 , respectively). The proportion of ontask turns increased significantly over time, $t(61)$ $=2.95, p<.01, d=.53$, and was moderately stable over the two time periods, $r=.56, p<.01$. Correlations with child global characteristic measures revealed that the child on-task proportion measure correlated with both children's CA, $r=$ $.35, p<.001$, and FSIQ, $r=.34, p<.01$, at Time 1 and with FSIQ, $r=.46, p<.001$, and TACL$\mathrm{R}, r=.38, p<.01$, at Time 2. Children were successful in their response to mothers' scaffolding attempts about half the time $(M s=.46$ and .55 at Times 1 and 2, respectively). Proportion of child success was also correlated with children's CA, $r=.44, p<.001$, and FSIQ, $r=.41, p<$ .01 , at Time 1 and with CA, $r=.31, p<.05$; FSIQ, $r=.48, p<.001$; TACL-R, $r=.38, p<$ .01 ; and EOWPVT-R, $r=.28, p<.05$, at Time 2 . Both the proportion of successful response, $t(61)=4.33, p<.001, d=.78$, and on-task proportion measures significantly increased over time, $t(61)=2.95, p<.01, d=.53$.

Mean level of scaffolding specificity was not correlated with any of the four global child characteristic measures at either time point. However, mothers did adjust their level of scaffolding specificity to their child's level of communication activity (communications per turn), being more specific when children were less active communicators, $r=-.45, p<.001$ at Time 1 and $r=-.35$, $p<.01$ at Time 2 . In addition, at Time 1 , higher levels of specificity were positively correlated with children's proportion of successful response, $r=$ .37, $p<.01$, and on-task proportion, $r=.32, p$ $<.05$. For Time 2, specificity was significantly correlated only with child successful response, $r$ $=.30, p<.05$.

\section{Discussion}

Mothers of children with developmental delays must make extensive adjustments to both the global characteristics and the specific social communication skills of their child in order to enhance mother-child interactions and to support their child's development. Adjustments must also occur in relation to context, varying in accordance with the goals of the interaction, (i.e., being primarily social or instructional). In this study, a comprehensive analysis of mothers' social communication and compliance patterns when engaging in social play and instructional tasks with their children who have developmental delays was carried out to examine the hypothesis that such adjustments do occur. The results of this investigation clearly support this hypothesis but, more importantly, provide new insights into the nature of mothers' adjustments to the characteristics of children with developmental delays and to task demands. Moreover, our results replicate and extend previous findings revealing that mothers' adjustments of their social communication patterns are not limited to children representing etiologic-specific subgroups, such as those with Down syndrome or to young children, because mothers of a heterogeneous group of 4- to 6-year-old children with delays continued to make adjustments over a 2-year period.

Specifically, mothers' adjustments were assessed in terms of their use of various forms of social communication in relation to their child's characteristics, their responsiveness to children's 
Table 6. Mother Scaffolding Frequencies in the Teaching Task for Both Time Points

\begin{tabular}{lrrrrr}
\hline & \multicolumn{2}{c}{ Time 1} & & \multicolumn{2}{c}{ Time 2 } \\
\cline { 2 - 3 } \cline { 5 - 6 } Scaffolding level & Mean & SD & & Mean & \multicolumn{1}{c}{$S D$} \\
\hline Level 0: None & 123.84 & 41.48 & & 118.31 & 47.73 \\
Level 1: General verbal start & 27.89 & 17.13 & & 19.58 & 11.12 \\
Level 2: Hint & 12.81 & 11.14 & & 18.47 & 9.16 \\
Level 3: Specific verbal instruction & 32.45 & 19.15 & & 36.24 & 19.53 \\
Level 4: Identify material or placement & 46.81 & 24.31 & & 35.66 & 17.84 \\
Level 5: Specify material and placement & 13.95 & 11.99 & & 7.44 & 7.04 \\
Level 6: Demonstrate & 5.58 & 11.38 & & 5.11 & 6.10 \\
Scaffolding specificity & 3.08 & .59 & & 3.02 & .44 \\
\hline
\end{tabular}

Note. $N=62$.

${ }^{a}$ Average of Levels 1-6.

requests and directives, their adaptations to task demands, and their use of scaffolding during a teaching task. As expected, mothers dominated the interaction as indicated by the number of total communications and communications per turn measures in both the free-play and teaching tasks at both time points. With respect to adjustments to children's global characteristics, we found that correlational analyses revealed that mothers communicated more overall with children who had lower cognitive and language levels, especially in the teaching task. Although mothers frequently employed directives, similar analyses also revealed that they were sensitive to their child's global characteristics, addressing a higher proportion of directives to children at lower cognitive levels at Time 1 for both tasks and to children at lower language levels at Time 2 for the teaching task. Of importance, analyses of the subcategories of mothers' directives indicated the use of a substantial proportion of suggestions, even to children at lower cognitive levels, a directive form that offered children choices. Moreover, a very small proportion of directives were efforts to restrict their child's behavior. Coupled with the finding that mothers addressed a higher proportion of statements to provide information to children at higher cognitive and language levels, it appears that mothers' adjustments are consistent with efforts to maintain a high level of interaction commensurate with their child's level of development (see Marfo, 1990).

The sensitivity of mothers to children's characteristics was further evident in the strong inverse relationship that was obtained between mothers' communications per turn and children's com- munications per turn, even after controlling for children's global characteristics of CA, cognitive and language levels, and behavior problems. Mothers were also consistent in their use of social communications to their child as revealed by the stability correlations across tasks, especially communications per turn. It appears that mothers were fine-tuning their overall level of social communications to the specific communicative ability of their child. For example, when more than one communication in a turn occurred, mothers often structured a directive by providing information to first orient the child, followed by the directive. On other occasions, directives were repeated in a slightly different form for emphasis and clarity. This compensatory mechanism enabled the dyad to maintain a level of interaction consistent with the child's characteristics and task demands.

Additional evidence for compensatory adjustments can be found in the maternal scaffolding analysis for the teaching task. Our results clearly reveal that mothers provided more specific information to children who had lower communication activity levels. This is consistent with findings of appropriate parent scaffolding for children and adolescents with intellectual disabilities in referential communication tasks (Abbeduto, Weissman, \& Short-Meyerson, 1999). Moreover, when higher levels of specificity were needed to assist children, they were more likely to respond successfully and, of even greater importance, remained on-task more often in the absence of mother scaffolding turns. This suggests that mothers were contributing to their child's independent functioning, although transferring knowledge gained from the dyadic interaction to indepen- 
dent activities may well remain a substantial problem for these children (see Landry et al., 1998).

Mothers' compliance to their children's requests and directives was high for both tasks and time periods, responding positively to their child's influence attempts nearly three quarters of the time on average. This high level of responsivity was independent of global child characteristics as well as more specific child social communication abilities. This high level of responsivity to children's influence attempts, despite extensive variability in all dimensions of children's characteristics, is consistent with a developmental pattern that fosters children's social development and reciprocity (Kochanska, 1992). Moreover, mothers' responsivity was unrelated to their overall use of directives in general and to the use of the imperative form. This replicates earlier work (e.g., Crawley \& Spiker, 1983; Roach et al., 1998), suggesting that responsiveness and directiveness are independent dimensions.

As expected, mothers adjusted their social communication patterns in accordance with task demands. Most apparent was the high proportion of mothers' directives expressed in the teaching task in comparison to the free-play task. Even in the teaching task, however, the control exercised through mothers' directives more often took the form of suggestions, thereby also encouraging their child to consider options and to make decisions. In the free-play task, correspondingly higher proportions of requesting information and making statements to their child were found. This suggests an increased effort on the part of mothers to achieve a more reciprocal or balanced exchange in this situation. However, the higher proportion of directives that were imperatives in the free-play task also indicates the difficulties experienced in these unstructured situations and the continuing need for mothers to provide clear direction for children with developmental delays (Landry et al., 1994).

Little systematic information is available on the developmental changes in the various forms of social communication for children with developmental delays in this age group, because even short-term longitudinal studies are the exception (Abbeduto \& Hesketh, 1997). Our findings indicate that, as expected, children's overall level of social communication activity increased over the 2-year period when interacting with their mothers in both tasks. The proportion of directives that were imperatives increased as well and, for the free-play task, children increased their proportional use of requests. Although these changes in children's social communications were rather modest, it nevertheless suggests that children became more active participants in social exchanges with their mothers over time. Moreover, moderate levels of stability for children were obtained for each social communication category over time, but especially in the more structured teaching task. We also note that children became more competent in the teaching task over time, increasing the proportion of both successful responses as well as on-task proportion.

In contrast, mothers' social communication patterns changed more substantially over time. For the free-play task, the proportion of statements increased over time, whereas the proportion of requests, directives, and directives that were imperatives decreased. Communications per turn did not change. For the teaching task, mothers' communications per their turn actually decreased over time, as they presumably became more efficient and explicit in their efforts to facilitate their now more competent child's performance on the task and were responding to their child's increased success at Time 2. As in the freeplay task, mothers' statements increased, and the proportions of directives and requests decreased. Mothers' social communications were moderately to highly stable over the 2-year period. This overall pattern indicates that mothers adjusted appropriately to their child's changing social communication abilities over time. They exerted less control as evidenced by the use of a smaller proportion of directives and requests and provided more information in the form of statements.

Taken together, our findings clearly suggest that mothers express forms of social communication appropriately linked to children's global abilities and to their social communication patterns and do so in a manner likely to achieve mothers' social and instructional goals. Mothers were also highly responsive to their child's influence attempts. Although there may be some subgroups of mothers who are so highly intrusive and dominating in these contexts as to limit or suppress the development of their children, the data in this correlational study are clearly consistent with the hypothesis that mothers' adjustments are well-adapted to the characteristics of their children with mild developmental delays, to task demands, and to children's emerging abilities over time. 
Although these conclusions are not limited to etiologic-specific subgroups or only young children, limits on generalizing these findings must nevertheless be considered. First, children with delays who also exhibited significant behavior problems were excluded from this study; yet they constitute approximately $25 \%$ of this population and create considerable parental stress (Baker et al., 2003) and control problems (Keogh, Garnier, Bernheimer, \& Gallimore, 2000). Similarly, gender may well exert an effect, but differences could not be examined because of the relatively small number of girls in our sample. Moreover, the impressive pattern of appropriate adjustments found in this study may be related to the fact that most of our families were intact with ample resources available to them, including access to early intervention and related supportive services. These families were also motivated to maximize their child's development as indicated by their interest in participating in the larger intervention study. As noted earlier, families at high levels of stress, irrespective of the source, were not included in our sample, and parental stress can influence aspects of parental directives (Girolametti \& Tannock, 1994). Nevertheless, this should not imply that the families in our study were not challenged to make adjustments to the many communicative, social, and behavioral problems exhibited by their children. Future work on adjustment patterns of mothers in families under considerable stress or children whose behavior is more difficult to manage may yield different outcomes. Additional studies that are focused on analyses of momentto-moment parent-child transactions will be useful as well (Landry et al., 1994; Roach et al., 1998) because they would further contribute to an understanding regarding how well parents are able to fine-tune their adjustments. As this information accumulates, it will further expand our knowledge of the factors governing parental adjustments to children with developmental delays and likely provide specific direction for intervention as well.

\section{References}

Abbeduto, L., \& Hesketh, L. J. (1997). Pragmatic development in individuals with mental retardation: Learning to use language in social interactions. Mental Retardation and Developmental Disabilities Research Revierws, 3, 323-334.

Abbeduto, L., Weissman, M. D., \& Short-Meyerson, K. (1999). Parental scaffolding of the dis- course of children and adolescents with mental retardation: The case of referential expressions. Journal of Intellectual Disability Research, 43, 540-557.

Abidin, R. R. (1995). Parenting Stress Index (3rd ed.). Odessa, FL: Psychological Assessment Resources.

Achenbach, T. M. (1991). Manual for the Child Behavior Checklist/4-18 and 1991 Profile. Burlington: University of Vermont, Department of Psychiatry.

Baker, B. L., McIntyre, L. L., Blacher, J., Crnic, K., Edelbrock, C., \& Low, C. (2003). Preschool children with and without developmental delay: Behaviour problems and parenting stress over time. Journal of Intellectual Disability Research, 47, 217-230.

Bell, R. Q. (1968). A reinterpretation of the direction of effects in studies of socialization. Psychological Review, 75, 81-95.

Black, B., \& Logan, A. (1995). Links between communication patterns in mother-child, fatherchild, and child-peer interactions and children's social status. Child Development, 66, 255-271.

Bornstein, M. H., \& Tamis-Lemonda, C. S. (1989). Maternal responsiveness and cognitive development in children. New Directions for Child Development, 48, 49-61.

Bradley, R. H. (2002). Environment and parenting. In M. H. Bornstein (Ed.), Handbook of parenting: Vol. 2. Biology and ecology of parenting (2nd ed., pp. 281-314). Mahwah, NJ: Erlbaum.

Bradley, R. H., \& Corwyn, R. F. (2004). "Family process" investments that matter for child well-being. In A. Kalil \& T. DeLeire (Eds.), Family investment in children's potential (pp. 132). Mahwah, NJ: Erlbaum.

Carrow-Woolfolk, E. (1985). Manual for the Test for Auditory Comprehension of Language-Revised. Allen, TX: DLM Teaching Resources.

Cielinski, K. L., Vaughn, B. E., Seifer, R., \& Contreras, J. (1995). Relations among sustained engagement during play, quality of play, and mother-child interaction in samples of children with Down syndrome and normally developing toddlers. Infant Behavior and Development, 18, 163-176.

Crawley, S. B., \& Spiker, D. (1983). Mother-child interactions involving two-year-olds with Down syndrome: A look at individual differences. Child Development, 54, 1312-1323. 
Gardner, M. F. (1990). Expressive One Word Picture Vocabulary Test-Revised. Novato, CA: Academic Therapy Publications.

Garvey, C. (1986). Peer relations and the growth of communication. In E. C. Mueller \& C. R. Cooper (Eds.), Process and outcome in peer relationships (pp. 329-345). San Diego: Academic Press.

Girolametti, L., \& Tannock, R. (1994). Correlates of directiveness in the interactions of fathers and mothers of children with developmental delays. Journal of Speech and Hearing Research, 37, 1178-1192.

Guralnick, M. J. (2002). Les jeunes enfants trisomiques 21 dans leurs relations avec des pairs: Caractéristiques de développement et interventions envisageables [The peer relations of young children with Down syndrome: Developmental characteristics and intervention approaches]. Journal de la Trisomie 21, No. 4, 1827.

Guralnick, M. J. (2006). Family influences on early development: Integrating the science of normative development, risk and disability, and intervention. In K. McCartney \& D. Phillips (Eds.), Blackwell handbook of early childhood development (pp. 44-61). Oxford, UK: Blackwell.

Guralnick, M. J., Connor, R. T., Neville, B., \& Hammond, M. A. (2006). Promoting the peer-related social development of young children with mild developmental delays: Effectiveness of a comprehensive intervention. American Journal on Mental Retardation, 111, 336-356.

Hecht, B. F., Levine, H. G., \& Mastergeorge, A. B. (1993). Conversational roles of children with developmental delays and their mothers in natural and semi-structured situations. American Journal on Mental Retardation, 97, 419-429.

Hodapp, R. M. (1995). Parenting children with Down syndrome and other types of mental retardation. In M. H. Bornstein (Ed.), Handbook of parenting: Volume I, Children and parenting (pp. 233-253). Mahwah, NJ: Erlbaum.

Hodapp, R. M. (2004). Behavioral phenotypes: Going beyond the two-group approach. In L. J. Glidden (Ed.), International review of research in mental retardation (Vol. 29, pp. 1-30). San Diego: Academic Press.

Hollingshead, A. B. (1975). Four factor index of social status. Unpublished manuscript, Yale Uni- versity, Department of Sociology, New Haven.

Keogh, B. K., Garnier, H. E., Bernheimer, L. P., \& Gallimore, R. (2000). Models of child-family interactions for children with developmental delays: Child-driven or transactional? American Journal on Mental Retardation, 105, 32-46.

Kochanska, G. (1992). Children's interpersonal influence with mothers and peers. Developmental Psychology, 28, 491-499.

Landry, S. H., Garner, P. W., Pirie, D., \& Swank, P. R. (1994). Effects of social context and mothers' requesting strategies on Down's syndrome children's social responsiveness. Developmental Psychology, 30, 293-302.

Landry, S. H., Miller-Loncar, C. L., \& Swank, P. R. (1998). Goal-directed behavior in children with Down syndrome: The role of joint play situations. Early Education and Development, 9, 375-392.

Landry, S. H., Smith, K. E., Swank, P. R., \& Miller-Loncar, C. L. (2000). Early maternal and child influences on children's later independent cognitive and social functioning. Child Development, 71, 358-375.

Mahoney, G. J., Fors, S., \& Wood, S. (1990). Maternal directive behavior revisited. American Journal on Mental Retardation, 94, 398-406.

Marfo, K. (1990). Maternal directiveness in interactions with mentally handicapped children: An analytical commentary. Journal of Child Psychology and Psychiatry, 31, 531-549.

Marfo, K. (1992). Correlates of maternal directiveness with children who are developmentally delayed. American Journal of Orthopsychiatry, 62, 219-233.

Maurer, H., \& Sherrod, K. B. (1987). Context of directives given to young children with Down syndrome and nonretarded children: Development over two years. American Journal of Mental Deficiency, 91, 579-590.

McCollum, J. A., \& Hemmeter, M. L. (1997). Parent-child interaction intervention when children have disabilities. In M. J. Guralnick (Ed.), The effectiveness of early intervention (pp. 549-576). Baltimore: Brookes.

Mitchell, F. (1979). Interobserver agreement, reliability, and generalizability of data collected in observational studies. Psychological Bulletin, 86, 376-390.

Pratt, M. W., Kerig, P., Cowan, P. A., \& Cowan, C. P. (1988). Mothers and fathers teaching 3- 
year-olds: Authoritative parenting and adult scaffolding of young children's learning. $D e-$ velopmental Psychology, 24, 832-839.

Roach, M. A., Barratt, M. S., Miller, M. J., \& Leavitt, L. A. (1998). The structure of mother-child play: Young children with Down syndrome and typically developing children. Developmental Psychology, 34, 77-87.

Rogoff, B., Ellis, S., \& Gardner, W. (1984). Adjustment of adult-child instruction according to child's age and task. Developmental Psychology, 20, 193-199.

Sacks, H., Schegloff, E. A., \& Jefferson, G. (1978). A simplest systematics for the organization of turn-taking of conversation. In J. Schenkein (Ed.), Studies in the organization of conversational interaction (pp. 7-57). New York: Academic Press.

Sparrow, S. S., Balla, D. A., \& Cicchetti, D. V. (1984). Vineland Adaptive Behavior Scales. Circle Pines, MN: American Guidance Service.

Spiker, D., Boyce, G. C., \& Boyce, L. K. (2002). Parent-child interactions when young children have disabilities. In L. M. Glidden (Ed.), International review of research in mental retardation (Vol. 25, pp. 35-70). San Diego: Academic Press.

Spiker, D., \& Hopmann, M. R. (1997). The effectiveness of early intervention for children with Down syndrome. In M. J. Guralnick (Ed.), The effectiveness of early intervention (pp. 271-305). Baltimore: Brookes.

Tannock, R. (1988). Mothers' directiveness in their interactions with their children with and without Down syndrome. American Journal on Mental Retardation, 93, 154-165.
Teti, D. M., \& Candelaria, M. (2002). Parenting competence. In M. H. Bornstein (Ed.), Handbook of parenting: Vol. 4. Applied parenting (2nd ed., pp. 149-180). Mahwah, NJ: Erlbaum.

Tomasello, M., \& Farrar, M. J. (1986). Joint attention and early language. Child Development, 57, 1454-1463.

Vygotsky, L. S. (1978). Mind in society. Cambridge: Harvard University Press.

Wechsler, D. (1989). Wechsler Preschool and Primary Scale of Intelligence-Revised. San Antonio: Psychological Corp.

Wechsler, D. (1991). Wechsler Intelligence Scale for Children (3rd ed.). San Antonio: Psychological Corp.

Wood, D., \& Middleton, H. (1975). A study of assisted problem solving. British Journal of Psychology, 66, 181-191.

Received 3/29/06, accepted 11/16/06.

Editor-in-charge: Leonard Abbeduto

This research was supported by a grant from the National Institute of Child Health and Human Development (RO1 HD37429). Support from Grant P30 HD02274 also facilitated our work. The authors thank the many coders and other staff members who participated in this project. Thanks are also extended to the participating families for helping us to better understand factors influencing mother-child interactions. Requests for reprints should be sent to Michael Guralnick, Center on Human Development and Disability, Seattle, WA 98195-7920. E-mail: mjgural@ washington.edu 